\title{
Study the Direction of Load on Bending Strength of Eucalyptus sp.
}

\author{
Ezhumalai Rajamanickam ${ }^{1 *}$, Karthik Ramesh Surapura ${ }^{2}$, Sukh Dev Sharma ${ }^{3}$ \\ ${ }^{1,3}$ Forest Product Division, Forest Research Institute, Dehradun, India \\ ${ }^{2}$ Deemed University, Wood Science \& Technology Student, Forest Research Institute, Dehradun, India
}

\begin{abstract}
*Address for Correspondence: Ezhumalai Rajamanickam, Forest products Division, Timber mechanics and Engineering Discipline, Forest Research Institute, New forest Post, Dehradun-248006, India

E-mail: rezhumalai@gmail.com
\end{abstract}

Received: 23 Sep 2020/ Revised: 10 Nov 2020/ Accepted: 04 Mar 2021

\begin{abstract}
Background: The direction of application of load has an appreciable effect on the strength properties of wood. While this is generally attributable to the presence of medullary rays in the radial direction and the difference in the alignment of cells, as viewed in the radial and tangential direction, it is interesting to note that in a large number of cases the properties in one direction can be predicted with a fair amount of accuracy from the properties in the other direction.

Methods: Bending Strength of wood specimens were tested on basis of IS: 1708 (Pt-5)-1986 and on the radial and tangential direction of the wood Specimen. Here loading in the radial direction means that load is applied to the tangential surface and loading in the tangential direction means that load is applied to the radial surface.

Result: The strength properties vary from species to species and application of direction of load. Loading direction appreciably affects the bending properties remarkably due to the anisotropic/ orthotropic nature of timber. The bending strength of timber, when loaded parallel to the direction of load is greater than that of timber loaded perpendicular to the direction of load.

Conclusion: It was observed that always MOE and MOR have greater value in the Radial surface. The direction of application of load has an appreciable effect on the strength properties of wood. While, this is generally attributable to the presence of medullary rays in the radial direction. The ratio of flexural strength values varied from $13 \%$ to $14 \%$ for Eucalyptus sp.
\end{abstract}

Key-words: Bending strength, Eucalyptus sp., Modulus of Elasticity (MOE), Modulus of Rupture (MOR)

\section{INTRODUCTION}

From beginning to now, timber is one of the most used construction materials. It is non-homogeneous and ${ }^{[1]}$ orthotropic having 3D figure. Although nowadays it is largely replaced by concrete, steel, plastic and fiber etc., the use of timber remains quite extensive ${ }^{[2]}$. Timber is subjected to various type of loading condition such as bending, compression, tension, shear, hardness, toughness, stiffness etc. The Variations in mechanical behavior due to changes not only in the inherent qualities of wood and conditions of testing but also in the size of specimens and direction of load applies ${ }^{[3]}$. The capability of timber to resist this loading condition is measured by the strength properties.

\section{How to cite this article}

Rajamanickam E, Surapura KR, Sharma D. Study the Direction of Load on Bending Strength of Eucalyptus sp. SSR Inst. Int. J. Life Sci., 2021; 7(2): 2781-2787.

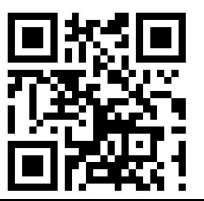

It is the mechanical properties that make wood suitable for different purposes i.e. construction and building and number of other uses of which furniture, vehicle, and flooring etc. are few examples ${ }^{[4]}$. Dependence of mechanical properties on factors like specific gravity, moisture content and temperature has attracted considerable attention of a few workers but dependence on size and shape of specimens and the direction of application of load has not received as much attention though it is fairly recognized in evaluating standard for tests. As a result, wood possesses material properties that may be significantly different from other materials normally encountered in structural design ${ }^{[5]}$. The direction of application of load has an appreciable effect on the strength properties of wood. One case study was Investigated tension perpendicular to grain properties in three different orientations, for radial, tangential and 45degree directions, using Sugar Maple specimens. Regarding the radial and tangential failure modes, it was observed that the typical failures were related to tension 
failure in the earlywood (juvenile wood) region of the specimens and probably with the strong contribution of the medullary rays, and for the inclined specimens, the tension failure is accompanied by shear failure along a growth ring ${ }^{[6]}$. Similar observation also got into analysis the compressive strength of column and beam; it is shown that compressive kinking strength of wood is governed mainly by its yield strength in shear and by certain features of its anatomy related to the so-called ray cells ${ }^{[7]}$.

Now the question is how to use the timber for particular purposes?. The answer is, where less surface area required, we can select the longitudinal direction. For example, poles or posts or columns, the same way while using wood for more surface area supporting to loadbearing structure as a beam or joist, we have to go for radial or tangential direction. In this care, there are no proper results that can insist on the best direction (radial or tangential) in wood that can hold the maximum load. Wood is an orthotropic material with unique and independent properties in different directions. Because of the orientation of the wood fibres, and how a tree increases in diameter as it grows, properties vary along three mutually perpendicular axis: longitudinal (L), radial $(\mathrm{R})$, and tangential $(\mathrm{T})^{[8,9]}$. Although wood properties differ in each of these three directions, differences between the radial and tangential directions are normally minor compared to their mutual differences with the longitudinal direction ${ }^{[9]}$. In Sri Lanka similar type of study was conducted in Ambalam structures; a cherished heritage structure originated from the vernacular architecture in Sri Lanka and it is revealed that those mediaeval constructors were knowledgeable on the deformation ${ }^{[10]}$. Grain orientation is important for three reasons. The direction of the grain affects the amount of deflection that occurs when loads are applied. It compromises load-bearing ability. Load bearing timber is stronger when forces are applied parallel to the grain than when force is applied perpendicular to the grain ${ }^{[10]}$. The bending strength and stiffness of laminated veneer lumber (LVL) produced from eucalyptus (Eucalyptus grandis $\mathrm{W}$. Hill ex Maiden) were analyzed. The results showed that the type of adhesive did not influence the bending properties of laminated veneer lumber. It can be stated that the differences among groups were due to differences in their densities. The direction of the load and the species of the tree had significant effects on the bending properties ${ }^{[11]}$.

Due to the orthotropic nature of the wood, it's essential to know that, is there any particular direction (radial or tangential) to be used? If use. There will be good opportunities in making the best use of wood. If no then without any effort wood can be used.

To address the above problem, in this paper, empirical study of stiffness (modulus of elasticity-MoE) and Bending strength/ flexural strength (modulus of ruptureMoR) in wood, mainly on radial and Tangential surface of Eucalyptus sp. wood were evaluated. Here loading in the radial direction means that load is applied to the tangential surface and loading in the tangential direction means that load is applied to the radial surface ${ }^{[12]}$.

\section{MATERIALS AND METHODS}

Sample preparation- The study was undertaken on Eucalyptus sp. wood species at Timber Mechanics and Engineering discipline, Forest Research Institute, Dehradun, India in May-2018. Nowadays these spp were widely used for furniture and construction sector. For standard evaluation of physical and mechanical properties, it is necessary to adopt a fixed methodology for selection of material, preparation of test samples and evaluation of results. The method of sampling model trees and logs for timber testing, followed at Forest Research Institute has since been standardized at the national level in IS: 2455-1974. Normally 5 to 10 trees of the species to be evaluated are selected from a locality randomly and one log of length 3 meters is taken from each tree. Logs are converted in the manner shown in Fig. 1 and the scantlings so obtained are marked and numbered accordingly.

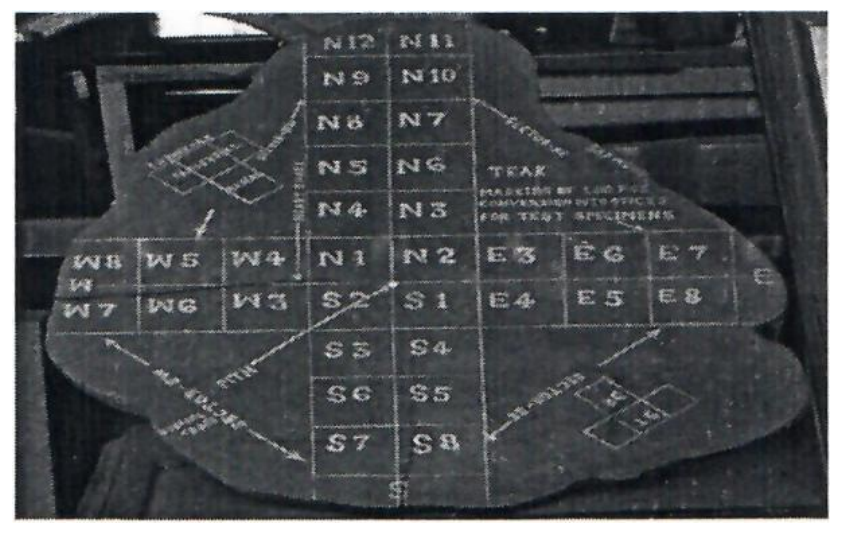

Fig. 1: Marking and Conversion of Logs into Sticks 
Marking and Conversion of Logs into Sticks- All logs were marked on the small end (top end) into $6 \times 6 \mathrm{~cm}$ squares as shown in Fig. 1 and sawn into nominal $6 \times 6 \mathrm{~cm}$ scantlings parallel to pith to pith axis. Each log shall be divided into bolts of $1.5 \mathrm{~m}$ length and each bolt was indicated by a letter of the alphabet in order, beginning with the one nearer the stump (Thus the $1.5 \mathrm{~cm}$ bolt above the stump was designated as bolt ' $A$ ' and the next above it as bolt ' $B$ ' and so on). When sticks, as marked out in Fig. 1 are taken out, each test stick shall have the complete identity mark of consignment number, tree number, the bolt designation and the stick number. All the connected sticks shall be matched for tests in the green and dry conditions as follows:

Green- All even-numbered sticks from the upper bolt and odd-numbered sticks from lower Bolt.

Dry- All even-numbered sticks from the lower bolt and odd-numbered sticks from upper Bolt. From these sticks small clear specimens are selected for conducting the physical and mechanical tests in green, kiln dry and/or air-dry conditions. Here the specimens are prepared from the materials available in Laboratory considering the different specific gravity range. The care was taken that the moisture content of all the species may nearly be the same to avoid the effect of moisture in strength. And converted into the desired size for testing purpose as per IS 1708(part 1-18)-1986 [13]. "Indian StandardMethod of testing of small clear specimens of timber" and also by ASTM-D-143 ${ }^{[14]}$. Each specimen is initially weighted correctly to the nearest gram and its dimensions measured correct to two decimal places of a centimetre. Before testing, four small discs of about $2 \times 2 \times 6 \mathrm{~cm}$ were taken for determination of specific gravity and moisture content of Eucalyptus sp. wood.

\section{Moisture content of the Samples}

Procedure: Eucalyptus sp. specimen was weighed to an accuracy of $.001 \mathrm{gm}$ in a weighing balance and dried in the oven. The specimens were dried in an oven at a temperature of $103 \pm 2^{\circ} \mathrm{C}$. The weight shall be recorded at regular intervals. The drying shall be considered to be complete when the variation between the last two weightings does not exceed $0.002 \mathrm{gm}$ until the mass is constant to $\pm 0.2 \%$ between two successive weightings made at an interval of not less than one hour.
Calculation- The moisture content expressed as a percentage of the oven-dry mass is given by the formula:

\section{Moisture content=}

Initial weight - Final weight/final weight $\times 100$

\section{Specific gravity of samples}

Procedure- The specimen shall be weighed correct to $0.001 \mathrm{gm}$. The Dimensions of the rectangular specimen shall be measured correct to $0.01 \mathrm{gm}$ and volume shall be calculated.

\section{Calculation- Specific gravity=}

$\frac{\text { weight of specimen }}{\text { volume of the speciment }} \times \frac{100}{100+\text { Moisture Content }}$

Rate of loading- The load shall be applied continuously during the test such that the movable head of the testing machine travels at a constant rate of $1 \mathrm{~mm}$ per minute irrespective of direction. The speed of the movable head of the testing machine as calculated by the following formula- $\mathbf{N}=\mathbf{Z L}^{2} / 6 \mathrm{D}$

Where: $\mathrm{N}=$ Rate of loading in $\mathrm{mm} / \mathrm{min}, \mathrm{Z}=$ Unit rate of fibre strain of outer fibre length/ $\min =0.0015, L=$ Span $(\mathrm{cm}), \mathrm{D}=$ Depth of the specimens

Recording of data and calculations- Static Bending Test (As per IS: 1708 (Pt-5)-1986.

Size $5 \times 5 \times 75 \mathrm{~cm}$, Span- $70 \mathrm{~cm}$,

Size $2 \times 2 \times 30 \mathrm{~cm}$, Span- $28 \mathrm{~cm}$

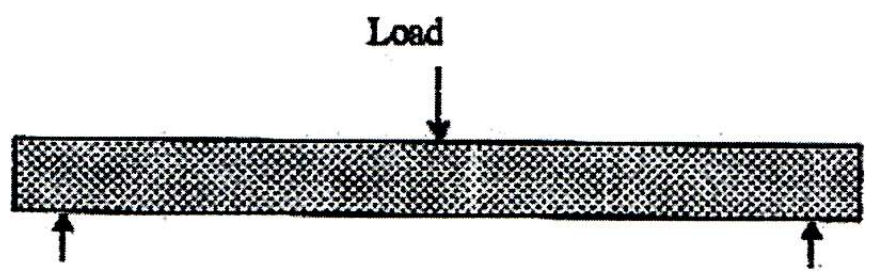

Fig. 2: Timber sample with span length, direction and place of loading

Continuously increasing load is applied centrally on the specimen such that the movable head of the testing machine moves at a constant rate of $2.5 \mathrm{~mm} / \mathrm{min}$ in case of standard size specimen and $1.0 \mathrm{~mm} / \mathrm{min}$ in case of small size specimen. Deflection was measured at suitable load intervals up to the maximum load. Beyond maximum load, the test is continued until a deflection of $15 \mathrm{~cm}$ for standard size and $6 \mathrm{~cm}$ for small size was attained or the specimen fails to support $100 \mathrm{~kg}$ load (standard size) or $20 \mathrm{~kg}$ load (small size), whichever was earlier. From load-deflection data, load and deflection at 
the proportional limit and maximum load were noted.

Test procedure- Bending tests were undertaken on the testing machine as per the standard test procedure. For Eucalyptus sp. eight replicates (total of 64 samples) were tested. The size of the sample was $30 \mathrm{~cm}$ in length and $2 \times 2 \mathrm{~cm}$ cross-section. The distance between points of supports (span) was $28 \mathrm{~cm}$. Test specimen shall be so placed on a rig that the load is applied through a loading block. The specimen shall be supported on the rig in such a way that it will be quite free to follow the bending action will not be restrained by friction.

\section{RESULTS}

From the data of the bending test, the modulus of rupture and modulus of elasticity has been determined by using the given formula on both the surface (radial and tangential surface). In the table, MOR, MOE, span length, Maximum load and load at elastic limit were recorded but the statistical analysis was done between MOR and MOE of tangential and redials Direction.

Species: Eucalyptus sp.

Surface: Radial

Direction of load: Tangential

$$
\begin{aligned}
& \text { Modulus of rupture }(\mathrm{MOR})=\mathbf{3} \mathbf{p}^{1} \mathrm{I} / \mathbf{2} \mathbf{b h}^{\mathbf{2}} \\
& \text { Modulus of elasticity }(\mathrm{MOE})=\mathbf{p l}^{3} / \mathbf{4 D b h ^ { 3 }}
\end{aligned}
$$

Where,

p-Applied load in kg at elastic limit, 1- Test span (cm), bBreadth of the specimen in $\mathrm{cm}$, h- Height of specimen $(\mathrm{cm}), \mathrm{P}^{1}$ - Maximum load $(\mathrm{kg}), \mathrm{D}$ - Deflection at elastic limit $(\mathrm{cm})$

Table 1 is about MOE and MOR of the radial surface of Eucalyptus sp. and Table 2 is MOE and MOR of Tangential surface of Eucalyptus sp. In our study, it was evident that a strength property depended upon the species and force direction of load. The test results have been presented in Table 1 and 2 .

Table 1: MOR and MOE values of Eucalyptus (Radial)

\begin{tabular}{ccccccccc}
\hline $\begin{array}{c}\text { Sample } \\
\text { No. }\end{array}$ & $\begin{array}{c}\text { Load at } \\
\text { E.L. }\end{array}$ & $\begin{array}{c}\text { Def. at } \\
\text { E.L. }\end{array}$ & $\begin{array}{c}\text { Max. } \\
\text { Load }\end{array}$ & Span & Width & Thickness & MOR & MOE \\
\hline 1 & 265 & 0.6 & 290 & 28 & 1.99 & 2.01 & 1515 & 150.0 \\
2 & 230 & 0.49 & 250 & 28 & 1.85 & 2.01 & 1428 & 171.5 \\
3 & 190 & 0.43 & 246 & 28 & 2.10 & 2.09 & 1142 & 126.5 \\
4 & 200 & 0.43 & 284 & 28 & 2.04 & 2.09 & 1366 & 137.1 \\
5 & 160 & 0.35 & 218 & 28 & 2.08 & 2.08 & 1040 & 134.0 \\
6 & 245 & 0.59 & 286 & 28 & 2.10 & 2.11 & 1305 & 115.5 \\
7 & 270 & 0.54 & 320 & 28 & 2.09 & 2.09 & 1499 & 143.8 \\
8 & 120 & 0.23 & 230 & 28 & 2.09 & 2.08 & 1068 & 152.2 \\
Avg. & & & & & & & 1278 & 141.3 \\
\hline
\end{tabular}

Species: Eucalyptus sp.

Surface: Tangential

Direction of load: Radial 
Table 2: MOR and MOE values of Eucalyptus (Tangential)

\begin{tabular}{ccccccccc}
\hline $\begin{array}{c}\text { Sample } \\
\text { No. }\end{array}$ & $\begin{array}{c}\text { Load at } \\
\text { E.L. }\end{array}$ & $\begin{array}{c}\text { Def. at } \\
\text { E.L. }\end{array}$ & $\begin{array}{c}\text { Max. } \\
\text { Load }\end{array}$ & Span & Width & Thickness & MOR & MOE \\
\hline 1 & 180 & 0.43 & 250 & 28 & 2.02 & 1.99 & 1313 & 144.3 \\
2 & 275 & 0.48 & 304 & 28 & 2.03 & 2.06 & 1509 & 177.2 \\
3 & 155 & 0.34 & 214 & 28 & 2.03 & 2.00 & 1131 & 154.1 \\
4 & 100 & 0.30 & 190 & 28 & 2.02 & 2.05 & 940 & 105.1 \\
5 & 140 & 0.34 & 190 & 28 & 2.13 & 2.11 & 842 & 112.9 \\
6 & 170 & 0.35 & 234 & 28 & 2.11 & 2.17 & 989 & 123.6 \\
7 & 145 & 0.35 & 224 & 28 & 2.11 & 2.08 & 1050 & 119.7 \\
8 & 160 & 0.32 & 270 & 28 & 2.10 & 2.09 & 1236 & 143.1 \\
Avg. & & & & & & & & 1117 \\
\hline
\end{tabular}

\section{DISCUSSION}

We were observed that the Modulus of rupture is consistently higher on the radial surface from the tangential surface. The modulus of elasticity also shows the same trend. But overall values of both the properties are higher when the load applied on the radial surface. one study elucidate the relationship between bending strength and loading direction was compared by changing the light acquisition point of wood surfaces to elucidate the anisotropy of the wood using NIRS in Cryptomeria japonica wood. Comparing the two loading directions, the result for the radial section was slightly superior to that of the tangential section. The radial section showed a good relationship between the spectra acquisition position and the arrangement of the wood's structure ${ }^{[15]}$. A similar result was also shown in poplar; fir, pine and hornbeam commonly used in Turkey were investigated. The compressive strength, flexural strength and toughness were determined both perpendicular and parallel to the grain. It was found that loading direction affects all mechanical properties remarkably ${ }^{[16]}$. A review paper concluded that fracture toughness perpendicular to the grain is greater than that parallel to the grain within a given species. Also, fracture toughness increases with increasing density and strain rate ${ }^{[17]}$. The study about Mechanical tests on small clear specimens of Eucalyptus globulus L was performed in Europe. The best correlations between ultimate stress and modulus of elasticity were found in bending and tension parallel to the grain ${ }^{[18]}$ and one more study in china shows that Oriented oblique strand lumber (Eucalyptus Strand Wood (ESWood)), which is manufactured from fastgrowing small diameter eucalyptus wood (Eucalyptus urophylla $\times E$. grandis). Small clear specimen tests were conducted to determine the mechanical properties of ESWood material. It appears that the strength and stiffness properties of ESWood are affected by grain directionality and glued layers ${ }^{[19]}$. The direction of loading also affects the joints in the wooden structure. Studies on the friction between wood members on grain direction and result indicate that normal force had almost no affection on the friction, however, there was the difference about friction was generated in wood to wood joint with normal force and it is different in the direction of wood grain ${ }^{[20]}$.

Loading on wood, ultimately it will affect the different cells of the wood. Here the specimens of four species with different cellular structures (white spruce, jack pine, white ash, and aspen) were tested in radial and tangential compression. The softwood and hardwood responses to radial compression were influenced by the anatomical features. Tangential compression on white spruce and jack pine specimens shows that the mechanisms of deformation in radial and tangential compression were distinctly different for these softwood species ${ }^{[21]}$. Still, more focus should be given to 
microstructure and its loading effect. A similar trend was shown on soft and hardwood sp. i.e. that the largest difference of the mean values of impact strength in the radial direction to the tangential direction was recorded for spruce wood, namely $50.3 \%$. Slightly smaller differences were observed for larch wood, i.e. $41.2 \%$. Minor differences of around $20 \%$ were recorded for beech, ash and oak wood. A difference with the opposite trend was recorded for birchwood rather than for the above-mentioned woods, namely $-9.5 \%$. Linden wood showed almost no difference $(-0.8 \%)$. About static bending strength, it was found that the largest difference (radial/tangential) was recorded for oak wood, i.e. 7.9\%, while smaller differences were found for linden wood amounting to $6.6 \%$ and birch $4.7 \%$. For spruce, larch, beech and ash wood, these differences are negligible ${ }^{[22]}$. Even in the wooden board, it was evaluated that integration over cross-sections along with the wooden board, an edgewise bending stiffness profile and a longitudinal stiffness profile, respectively, were calculated. A new Indicating Properties and bending strength were defined as the lowest bending stiffness determined along with the board ${ }^{[23]}$. Timber-concrete composite (TCC) was used in $20^{\text {th }}$-century buildings and its load distribution capacity of analyzed transversally and longitudinally and found that mechanically "loaded beam" can receive less than $50 \%$ of the concentrated point load ${ }^{[24]}$. So we can use the wood in a tangential direction also. An investigating of the effects of embedment side and loading direction on the embedment strength of Cross-laminated Timbers (CLT) shows that the embedment side, loading direction and the thickness ratio of the transverse layer (TRTL) of CLT had significant influences on CLT embedment properties. When the transverse and longitudinal layers shared the dowel embedment load jointly, CLT had better ductility ${ }^{[25]}$. The above reference and also experiments result in shows that there is a significant difference was observed in direction of loading in eucalyptus $\mathrm{sp}$.

\section{CONCLUSIONS}

The bending strength of timber when loaded parallel to the direction of load was greater than that of timber loaded perpendicular to the direction of load. The ratio of flexural strength values varied from $13 \%$ to $14 \%$ for Eucalyptus sp. The statistical analysis shows that nonsignificant $\mathrm{MOE}$ is the difference between radial and tangential direction but in the case of $\operatorname{MOR}(t=1.6)$. It was significantly different at $95 \%$ confidence level. For all sort of construction purposes, it is better to apply load on tangential. Investigations, as the samples take fewer loads in this direction. However, more attention should be placed on natural defects and other timber defects which have more effect on the strength of the timber.

Overall strength properties of wood depend on the individual cells and their orientation. Further study is needed for its microstructure of the wood and its strength properties.

\section{CONTRIBUTION OF AUTHORS}

Research Concept- R. Ezhumalai, Sukh Dev Sharma

Research design- Ezhumalai Rajamanickam, Karthik Ramesh Surapura, Sukh DevSharma.

Supervision- Ezhumalai Rajamanickam, Sukh Dev Sharma

Materials- Karthik Ramesh Surapura

Data collection- Karthik Ramesh Surapura

Data analysis and Interpretation- Ezhumalai Rajamanickam, Karthik Ramesh Surapura

Literature search- Ezhumalai Rajamanickam, Karthik Ramesh Surapura

Writing Article- Ezhumalai Rajamanickam, Karthik Ramesh Surapura, Sukh Dev Sharma

Critical Review- Ezhumalai Rajamanickam, Sukh Dev Sharma

Article Editing- Ezhumalai Rajamanickam, Karthik Ramesh Surapura

Final Approval- Ezhumalai Rajamanickam, Sukh Dev Sharma

\section{REFERENCES}

[1] Green DW, Winandy JE, Kretschmann DE. Mechanical properties of wood. In Wood HandbookWood as an Engineering Material. Madison, WI, USA; US Department of Agriculture Forest Products Laboratory publication: 1999; Chapter 4.

[2] Ezhumalai R, Karthik RS, Sharma SD. The Effect of Direction of Load on Bending Strength of Melia compositae. International Journal of Natural Resource Ecology and Management, 2021; 6(1): 1-5. doi: 10.11648/j.ijnrem.20210601.11.

[3] JM Dinwoodie. Timber: its nature and behaviour. $2^{\text {nd }}$ ed., Landon \& New York; CRC Press: 2002; pp. 91-93.

[4] Dennis Jones, Christian Brischke. 2- Wood as biobased building material, Performance of Bio-based Building Materials. Duxford, United Kingdom; Woodhead Publishing, 2017; pp. 21-96. 
[5] Michael H Ramage, et al. The wood from the trees: The use of timber in construction. Renewable and Sustainable Energy Reviews, 2017; 68(1): 333-59.

[6] Mascia NT, Kretschmann DE, Ribeiro AB. Evaluation of Tension Perpendicular to Grain Strengths in Small Clear Samples of Sugar Maple for Radial, Tangential and 45-Degree Loading Directions. Materials Res., 2020; 23(3): e20190323.

[7] Benabou L. Kink Band Formation in Wood Species under Compressive Loading. Experimental Mechanics, 2008; 48(5): 647-56.

[8] David EK. Wood handbook- Wood as an engineering material. Chapter-5 Mechanical Properties of Wood, General Technical Report FPL-GTR-190. Madison, WI: U.S. Department of Agriculture, Forest Service, Forest Products Laboratory: 2010; pp. 1-5.

[9] Ritter MA. Timber Bridges: Design, Construction, Inspection, and Maintenance. Washington, DC, US Government Press: 1990; pp. 3-6.

[10]Mendis MS, Halwatura RU, Somadeva DRK, et al. Influence of timber grain distribution on orientation of saw cuts during application: Reference to heritage structures in Sri Lanka. Case Studies in Construction Materials, 2019; 11: 1-18.

[11]Bal B, Bektas I. The effects of wood species, load direction, and adhesives on bending properties of laminated veneer lumber. BioResources, 2012; 7: 3104-12.

[12]Ezhumalai R, Karthik RS, Sharma SV. The Effect of Direction of Load on flexural Strength of Pinus radiata wood. Int J Res Appl Natural Socl Sci., 2021; 9(2): 9-16.

[13]IS 1708 (Parts 1 to 18): 1986. Indian Standard Method of tests of small clear specimens of timber (second revision), New Delhi, Bureau of Indian Standards: 2005; pp. 1-63.

[14]ASTM D143-14, Standard Test Methods for Small Clear Specimens of Timber, West Conshohocken, PA, ASTM International publication: 2014; pp. 1-31. www.astm.org.

[15]Kurata Y. A Comparison of the Loading Direction for Bending Strength with Different Wood Measurement Surfaces Using Near-Infrared Spectroscopy. Forests, 2020; 11(6): 644 .
[16]Aydin S, Yardimci M Y, Ramyar K. Mechanical properties of four timber species commonly used in Turkey. Turkish J Eng Environ Sci., 2007; 31(1): 19-27.

[17]Conrad M P C, Smith G D, Fernlund G. Fracture of solid wood: a review of structure and properties at different length scales. Wood and Fiber Sci., 2003; 35(4): 570- 84.

[18]Jiawei C, Haibei X, Zhifang W, Linqing Y. Mechanical Properties of a Eucalyptus-Based Oriented Oblique Strand Lumber for Structural Applications. J. of Renewable Materials, 2019; 7(11): 1147-64.

[19]Crespo J, Majano-Majano A, Lara-Bocanegra AJ, Guaita M. Mechanical Properties of Small Clear Specimens of Eucalyptus globulus Labill. Materials (Basel), 2020; 13(4): 906.

[20]Park CY, Kim CK, Kim HK, Lee JJ. Evaluation of Friction Properties According to Normal Force and Direction of Wood Grain in Real Contact Area. Journal of the Korean Wood Science and Technology, 2011; 39(5): 437-43.

[21]Taghi T, Ying HC. Characterizing Microscopic behavior of wood under Transverse compression. Part 11. Effect of species and loading direction. Wood and Fiber Sciences, 2001; 33(2): 223-32.

[22]Vlastimil B, David N, Premysl S. Comparison and Analysis of Radial and Tangential Bending of Softwood and Hardwood at Static and Dynamic Loading. Forests, 2020; 11: 896.

[23]Olsson A, Oscarsson J, Serrano E, Källsner B, Johansson $\mathrm{M}$, et al. Prediction of timber bending strength and in-member cross-sectional stiffness variation on the basis of local wood fibre orientation. Eur J Wood Pro., 2013; 71: 319-33.

[24]Sandra M, Alfredo D, Sergio L. Distribution of Concentrated Loads in Timber-Concrete Composite Floors: Simplified Approach, Buildings, 2020; 10(2): 32.

[25]Dong W, Li Q, Wang Z, Zhang $\mathrm{H}$, Lu X et al. Effects of embedment side and loading direction on embedment strength of cross-laminated timber for smooth dowels. Eur J Wood Prod., 2020; 78(3): 1-9. 